\title{
Atomic Structure of the (001) Surface of $\mathrm{CuGaSe}_{2}$
}

\author{
Leandro Liborio* and Su Chuen Chew \\ TYC, The London Centre for Nanotechnology, \\ Imperial College London, London SW7 2AZ, United Kingdom \\ Nicholas Harrison \\ TYC, The London Centre for Nanotechnology, \\ Imperial College London, London SW7 2AZ, United Kingdom \\ and STFC, Daresbury Laboratory, Daresbury, \\ Warrington WA4 4AD, United Kingdom
}

\begin{abstract}
Hybrid exchange density functional theory is used to study the wide band gap chalcopyrite $\mathrm{CuGaSe}_{2}$. The formation energies of the experimentally observed $(4 \times 1)$ and $(1 \times 1)$ atomic scale reconstructions on the $\mathrm{CuGaSe}_{2}(001)$ surface are calculated for different environmental conditions. The results suggest that a Serich $(1 \times 1)$ reconstruction, and a $\mathrm{Cu}$-poor, Se-rich $(4 \times 1)$ reconstruction, are the only stable surfaces under all the studied environmental conditions. Two complementary mechanisms for the stabilisation of $\mathrm{CuGaSe}_{2}$ surfaces are proposed, and it is suggested that the presence of $\mathrm{Na}$ stabilises the $(4 \times 1)$ reconstructions, making them the stable terminations under Na-rich conditions.
\end{abstract}

PACS numbers:

*Electronic address: 1.liborio@imperial.ac.uk 


\section{INTRODUCTION}

Ternary I-III-VI 2 chalcopyrite compounds $\left(\mathrm{CuInSe}_{2}, \mathrm{CuGaSe}_{2}\right.$ and $\left.\mathrm{Cu}(\mathrm{In} / \mathrm{Ga}) \mathrm{Se}_{2}\right)$ are promising materials for photoelectronic devices such as solar cells [1, 2]. These devices are usually multilayered thin-film heterostructures in which the absorber layer is made of a chalcopyrite thin film that is epitaxially grown, in some cases using Molecular Organic Chemical Vapour Deposition (MOCVD). MOCVD is a reliable technique for the fabrication of high-efficiency solar cells [3], and solar cells with efficiencies between $10 \%$ and $19 \%$ can be obtained. More generally, efficiencies of the order of $20 \%$, measured under the AM 1.5 global spectrum for $1000 \mathrm{~W} / \mathrm{m} 2$ irradiance, have been achieved in the lab for epitaxially grown $\mathrm{CuIn}_{x} \mathrm{Ga}_{(1-x)} \mathrm{Se}_{2}$-based solar cells [4, 5]. There are other methods to grow chalcopyrite thin films. For instance, single-crystal surfaces such as CuInSe2(112) and (110) [6,7] and surfaces of polycrystalline CuInSe2 [? ], have been prepared with the sputtering/annealing processing used by Denizou et. al. in the synthesis of the (001) surfaces of $\mathrm{CuGaSe}_{2}$ that we have studied in this work. They grew single crystalline (001) $\mathrm{GuGaSe}_{2}$ surfaces which were $\mathrm{Ar}^{+}$sputtered and annealed [8, 9], and their atomic surface structures and compositions were analysed using low energy electron diffraction (LEED) and Auger electron spectroscopy (AES). Denizou et. al. observed clean, stable, unfacetted, nonstoichiometric $(4 \times 1)$ reconstructions on the (001) surface of $\mathrm{GuGaSe}_{2}$, with a Se-rich, Cu-poor stoichiometry[8].

According to Tasker's classification[10], the stoichiometric, unreconstructed (001) $\mathrm{GuGaSe}_{2}$ surface is a polar surface. But the (001) surfaces of $\mathrm{CuGaSe}_{2}$ that we have studied here have been reconstructed, and are non-stoichiometric and non-polar. Experimental studies have been performed to characterise the (112) and (110) surfaces of CuInSe 2 single crystals[11]. As regards the experimental evidence on the $\mathrm{CuGaSe}_{2}$ surfaces, Meeder and coworkers grew crystalline $\mathrm{CuGaSe}_{2}$ samples and showed that the surfaces tend to be $\mathrm{Cu}$-depleted and, if grown on soda-lime type of substrates, Na-rich[12].

Non-polar, non-stoichiometric (001) surfaces of $\mathrm{CuGaSe}_{2}$ are relevant in the field of photovoltaic applications. For instance, surface-faceting is stronger on $\mathrm{CuInSe}_{2}(001)$ surfaces as com- 
pared to $\mathrm{CuGaSe}_{2}$ (001) surfaces, which implies that the $\mathrm{CuGaSe}_{2}$ (001) surfaces are more stable than the $\mathrm{CuGaSe}_{2}$ (112) surfaces. Non-stoichiometry is a stabilising factor in the $\mathrm{CuGaSe}_{2}(001)$ surfaces when compared to the $\mathrm{CuInSe}_{2}$ (001) surfaces [13]. Moreover, non-stoichiometric (001) surfaces of $\mathrm{CuGaSe}_{2}$ play an important role in the study of the grain boundaries of $\mathrm{CuGaSe}_{2}$ [1].

However, when the absorber layer is only composed of a $\mathrm{CuGaSe}_{2}$ thin film, the devices show efficiencies of, at most, 9.5\% [14]. $\mathrm{CuIn}_{x} \mathrm{Ga}_{(1-x)} \mathrm{Se}_{2}$ is made from substituting Ga atoms with In atoms in $\mathrm{CuGaSe}_{2}$, and it is well-known that, to improve the efficiencies of chalcopyrite-based solar cells, the surface and interface properties of the chalcopyrites forming the different layers need to be understood[13].

In this work, we use $a b$ initio thermodynamics to study the stability, under different environmental conditions, of several $(4 \times 1)$ surface reconstructions. The atomic structure of these reconstructions is proposed on the basis of the experimental evidence and the computed relaxation of the surface layers. The role of $\mathrm{Na}$ in the surface's stability is also studied.

\section{METHODOLOGY}

\section{A. Computational Details}

Density functional theory (DFT) calculations were performed using CRYSTAL [15] and the Becke, three-parameter, Lee-Yang-Parr hybrid exchange functional (B3LYP). This functional has been shown to provide a reliable description of the electronic structure, geometry and energetics in a wide range of materials [16, 17]. In particular, hybrid exchange functionals such as B3LYP provide a much better prediction of the band gap of semiconductors than the local density approximation (LDA) or generalised gradient approximation (GGA) DFT functionals, and are therefore likely to be more accurate in estimating the valence band offset of semiconductor heterojunctions [18].

Polarised triple valence Gaussian basis sets [15] for copper $(\mathrm{Cu})$, gallium $(\mathrm{Ga})$, sodium $(\mathrm{Na})$ and selenium (Se) were used throughout. For the Se, the outer diffuse Gaussian has been removed 
and valence functions reoptimized for the solid. In CRYSTAL, real space summations of the Coulomb and exchange contributions to the Hamiltonian matrix are controlled by five overlap criteria. In these calculations, four of these overlap criteria have values of $10^{-6}$ and the last one has a value of $10^{-12}$. The control of these approximations is described in detail elsewhere [19]. A Monkhorst-Pack shrinking factor of eight was used to sample the first Brillouin zone, and a Gilat net of eight points was used in the evaluation of the Fermi energy and density matrix [19]. The bulk $\mathrm{CuGaSe}_{2}$ is optimised for lattice parameters and atomic positions, whereas the relaxation of the atomic coordinates is performed for the surface reconstructions only.

All the surface structures were represented by periodically repeated symmetric slabs consisting of seven layers of Se atoms and $\mathrm{CuGa}$ atoms in the (001) direction. Test calculations with $(1 \times 1) \mathrm{Se}$ and $\mathrm{CuGa}$ terminated slabs, with a number of layers ranging from 5 up to 17 , showed variations of the surface energy smaller than $0.015 \mathrm{~J} / \mathrm{m}^{2}$. All the surface reconstructions studied in this work were simulated using symmetric slabs of 13 layers. These slabs have a centre of inversion: the simulated (001) surfaces are non-polar and non-stoichiometric

\section{B. Surface Energies}

Total energy electronic structure calculations can be combined with thermodynamics in order to deduce the stable structures of complex surfaces over a range of environmental conditions. The equilibrium surface stoichiometry and free energy is actually a statistical average over all elementary adsorption and desorption processes from and to a particle reservoir. When the total number of adsorbtion processes equals the total number of desorption processes, the average surface composition and structure remains constant and the surface has achieved thermodynamic equilibrium with the environment. Our approach is based in the methodology developed by A. Zunger and coworkers for calculating the surface energies of chacopyrites [20-22].

At thermodynamic equilibrium, the energy of different surface reconstructions in the ternary compound $\mathrm{CuGaSe}_{2}$ is given by: 


$$
\begin{aligned}
\gamma(\mathrm{T}, \mathrm{p})= & \frac{1}{2 \mathrm{~A}}\left[\left(\mathrm{G}^{\mathrm{slab}}\left(\mathrm{T}, \mathrm{p}, \mathrm{n}_{\mathrm{Cu}}, \mathrm{n}_{\mathrm{Ga}}, \mathrm{n}_{\mathrm{Se}}\right)-\mathrm{n}_{\mathrm{Cu}} \mu_{\mathrm{Cu}}(\mathrm{T}, \mathrm{p})\right.\right. \\
& \left.-\mathrm{n}_{\mathrm{Ga}} \mu_{\mathrm{Ga}}(\mathrm{T}, \mathrm{p})-\mathrm{n}_{\mathrm{Se}} \mu_{\mathrm{Se}}(\mathrm{T}, \mathrm{p})\right]
\end{aligned}
$$

Since it is assumed that $\mathrm{CuGaSe}_{2}$ is in equilibrium with its elemental components:

$$
\mathrm{G}_{\mathrm{CuGaSe}_{2}}^{\mathrm{bulk}}(\mathrm{T}, \mathrm{p})=\mu_{\mathrm{Cu}}(\mathrm{T}, \mathrm{p})+\mu_{\mathrm{Ga}}(\mathrm{T}, \mathrm{p})+2 \mu_{\mathrm{Se}}(\mathrm{T}, \mathrm{p})
$$

equations 2 and 1 can be combined to express the energy of a surface reconstruction in $\mathrm{CuGaSe}_{2}$ as:

$$
\begin{aligned}
\gamma(\mathrm{T}, \mathrm{p}) & =\frac{1}{2 \mathrm{~A}}\left[\mathrm{G}^{\text {slab }}\left(\mathrm{T}, \mathrm{p}, \mathrm{n}_{\mathrm{Cu}}, \mathrm{n}_{\mathrm{Ga}}, \mathrm{n}_{\mathrm{Se}}\right)-\left(\frac{\mathrm{n}_{\mathrm{Se}}}{2}\right) \mathrm{G}_{\mathrm{CuGaSe}_{2}}^{\text {bulk }}(\mathrm{T}, \mathrm{p})\right. \\
& \left.+\left(\left(\frac{\mathrm{n}_{\mathrm{Se}}}{2}\right)-\mathrm{n}_{\mathrm{Cu}}\right) \mu_{\mathrm{Cu}}(\mathrm{T}, \mathrm{p})+\left(\left(\frac{\mathrm{n}_{\mathrm{Se}}}{2}\right)-\mathrm{n}_{\mathrm{Ga}}\right) \mu_{\mathrm{Ga}}(\mathrm{T}, \mathrm{p})\right]
\end{aligned}
$$

Defining $\Delta \mu_{\mathrm{i}}=\mu_{\mathrm{i}}(\mathrm{T}, \mathrm{p})-\mu_{\mathrm{i}}^{\circ}$, where $\mu_{\mathrm{i}}^{\circ}$ is the chemical potential at standard conditions $(T=$ $298 \mathrm{~K}, p=1 \mathrm{~atm})$, the surface energy can be re-written as:

$$
\begin{aligned}
\gamma(\mathrm{T}, \mathrm{p}) & =\frac{1}{2 \mathrm{~A}}\left[\mathrm{G}^{\mathrm{slab}}\left(\mathrm{T}, \mathrm{p}, \mathrm{n}_{\mathrm{Cu}}, \mathrm{n}_{\mathrm{Ga}}, \mathrm{n}_{\mathrm{Se}}\right)-\left(\frac{\mathrm{n}_{\mathrm{Se}}}{2}\right) \mathrm{G}_{\mathrm{CuGaSe}_{2}}^{\text {bulk }}(\mathrm{T}, \mathrm{p})\right. \\
& +\left(\left(\frac{\mathrm{n}_{\mathrm{Se}}}{2}\right)-\mathrm{n}_{\mathrm{Cu}}\right) \mu_{\mathrm{Cu}}^{\circ}+\left(\left(\frac{\mathrm{n}_{\mathrm{Se}}}{2}\right)-\mathrm{n}_{\mathrm{Ga}}\right) \mu_{\mathrm{Ga}}^{\circ} \\
& \left.+\left(\left(\frac{\mathrm{n}_{\mathrm{Se}}}{2}\right)-\mathrm{n}_{\mathrm{Cu}}\right) \Delta \mu_{\mathrm{Cu}}+\left(\left(\frac{\mathrm{n}_{\mathrm{Se}}}{2}\right)-\mathrm{n}_{\mathrm{Ga}}\right) \Delta \mu_{\mathrm{Ga}}\right]
\end{aligned}
$$

As it is assumed that the solid bulk $\mathrm{CuGaSe}_{2}$ is in equilibrium, the upper bound of $\mu_{i}$ is the chemical potential of the corresponding element in its standard state, as to avoid precipitation of the element, that is:

$$
\Delta \mu_{\mathrm{i}} \leq 0
$$

We would like to know the region in the phase space where $\mathrm{CuGaSe}_{2}$ is stable. In this region, 
Equation 2 must hold true and, considering equation 5 , it can be re-written as:

$$
\Delta \mathrm{G}_{\mathrm{CuGaSe}_{2}}=\Delta \mu_{\mathrm{Cu}}+\Delta \mu_{\mathrm{Ga}}+2 \Delta \mu_{\mathrm{Se}}
$$

where $\Delta \mathrm{G}_{\mathrm{CuGaSe}_{2}}$ is the Gibbs free energy of formation of $\mathrm{CuGaSe}_{2}$. The chemical potentials are further restricted by other competing phases. In this work, the competing phases being considered are $\mathrm{CuGa}_{5} \mathrm{Se}_{8}, \mathrm{Cu}_{3} \mathrm{Se}_{2}$ and GaSe. Therefore:

$$
\begin{array}{r}
3 \Delta \mu_{\mathrm{Cu}}+3 \Delta \mu_{\mathrm{Se}} \leq \Delta \mathrm{G}_{\mathrm{Cu}_{3} \mathrm{Se}_{2}} \\
\Delta \mu_{\mathrm{Ga}}+\Delta \mu_{\mathrm{Se}} \leq \Delta \mathrm{G}_{\mathrm{GaSe}} \\
\Delta \mu_{\mathrm{Cu}}+5 \Delta \mu_{\mathrm{Ga}_{8}}+\Delta \mu_{\mathrm{Se}} \leq \Delta \mathrm{G}_{\mathrm{CuGa}_{5} \mathrm{Se}_{8}}
\end{array}
$$

If the surface is doped with an extrinsic dopant such as $\mathrm{Na}$, the Gibbs formation energy of Nacompeting phases such as $\mathrm{Na}_{2} \mathrm{Se}$ need to be considered as well. This phase adds an additional constraint to the system.

$$
2 \Delta \mu_{\mathrm{Na}}+\Delta \mu_{\mathrm{Se}} \leq \Delta \mathrm{G}_{\mathrm{Na}_{2} \mathrm{Se}}
$$

The values of the chemicals potentials of $\mathrm{Cu}, \mathrm{Ga}$ and $\mathrm{Se}$ for which $\mathrm{CuGaSe}_{2}$ is stable have been determined by combining equations (6) and (7), and are represented by the white region in Figure 3. Within this region, the limiting values of $\Delta \mu_{\mathrm{Se}}$ are given by:

$$
\frac{\Delta \mathrm{G}_{\mathrm{CuGaSe}_{2}}}{2} \leq \Delta \mu_{S e} \leq 0
$$

These values for $\Delta \mu_{\mathrm{Se}}$ are then used in equation $(10)$ to calculate the limiting values of $\Delta \mu_{\mathrm{Na}}$, which is then used in the calculation of the surfaces energies of Na-doped surfaces. 
fore, they are usually approximated [23 25]. In this case, the approximations are applied when defining the variational limits of $\Delta \mu_{i}(i=\mathrm{Cu}, \mathrm{Ga}, \mathrm{Se})$, which is done through the formation energies of $\mathrm{CuGaSe}_{2}$ and its competing phases. In the following, the methodology is exemplified using the Gibbs formation energy of $\mathrm{CuGaSe}_{2}$, which is defined in equation (6). This equation can be written as follows:

$$
\begin{aligned}
\Delta \mathrm{G}_{\mathrm{CuGaSe}_{2}}=\mathrm{G}_{\mathrm{CuGaSe}_{2}}-\mathrm{G}_{\mathrm{Ga}}-\mathrm{G}_{\mathrm{Cu}}-2 \mathrm{G}_{\mathrm{Se}} \\
=\mathrm{E}_{\mathrm{CuGaSe}_{2}}^{\mathrm{DFT}}-\mathrm{E}_{\mathrm{Cu}}^{\mathrm{DFT}}-\mathrm{E}_{\mathrm{Ga}}^{\mathrm{DFT}}-2 \mathrm{E}_{\mathrm{Se}}^{\mathrm{DFT}} \\
+\mathrm{F}_{\mathrm{CuGaSe}_{2}}^{\mathrm{vib} .} \mathrm{F}_{\mathrm{Cu}}^{\mathrm{vib} .}-\mathrm{F}_{\mathrm{Ga}}^{\mathrm{vib} .}-2 \mathrm{~F}_{\mathrm{Se}}^{\mathrm{vib} .} \\
+\mathrm{p}\left(\mathrm{V}_{\mathrm{CuGaSe}_{2}}-\mathrm{V}_{\mathrm{Cu}}-\mathrm{V}_{\mathrm{Ga}}-2 \mathrm{~V}_{\mathrm{Se}}\right)
\end{aligned}
$$

In this equation, the Gibbs free energy, $\mathrm{G}=\mathrm{E}-\mathrm{TS}+\mathrm{pV}$, is written as

$$
\mathrm{G}=\mathrm{E}^{\mathrm{DFT}}+\mathrm{F}^{\mathrm{vib}}+\mathrm{pV} \text {. }
$$

$\mathrm{E}^{\mathrm{DFT}}$ is the $a b$ initio total energy of the material, $\mathrm{F}^{\mathrm{vib} .}=\mathrm{E}^{\mathrm{vib} .}-\mathrm{TS}^{\mathrm{vib}}$ is the Helmholtz vibrational energy [23], which depends on the phonons and is a function of temperature, and $p V$ is the pressure-volume term.

The $\mathrm{pV}$ and $\mathrm{F}^{\mathrm{vib}}$. terms are small for crystalline incompressible materials such as $\mathrm{CuGaS}_{2}$, and equation 12 uses differences between these quantities to define the $\Delta \mu_{i}$ variational limits. Consequently, the $\mathrm{pV}$ and $\mathrm{F}^{\mathrm{vib}}$. contributions for these type of materials are of the order of 0.02 $\mathrm{J} / \mathrm{m}^{2}$ [23, 25, 26], and can be considered negligible. Therefore, $\Delta \mathrm{G}_{\mathrm{CuGaS}_{2}}$ can be written as:

$$
\Delta \mathrm{G}_{\mathrm{CuGaSe}_{2}}=\mathrm{E}_{\mathrm{CuGaSe}_{2}}^{\mathrm{DFT}}-\mathrm{E}_{\mathrm{Cu}}^{\mathrm{DFT}}-\mathrm{E}_{\mathrm{Ga}}^{\mathrm{DFT}}-2 \mathrm{E}_{\mathrm{Se}}^{\mathrm{DFT}}
$$

where $\mathrm{E}_{\mathrm{CuGaSe}_{2}}^{\mathrm{DFT}}, \mathrm{E}_{\mathrm{Cu}}^{\mathrm{DFT}}, \mathrm{E}_{\mathrm{Ga}}^{\mathrm{DFT}}$ and $\mathrm{E}_{\mathrm{Se}}^{\mathrm{DFT}}$ are the ab initio total energies of these materials in their solid standard states. $\mathrm{E}_{\mathrm{CuGaSe}}^{\mathrm{DFT}}$ is the total energy of bulk $\mathrm{CuGaSe}_{2}$ in its tetragonal phase and $\mathrm{E}_{\mathrm{Se}}^{\mathrm{DFT}}$ is calculated in its pure orthorombic $\alpha$ phase 27]. As regards $\mathrm{Cu}$ and Al, the B3LYP approximation 
does not provide accurate energies for metals and, therefore, $\mathrm{E}_{\mathrm{Cu}}^{\mathrm{DFT}}$ and $\mathrm{E}_{\mathrm{Ga}}^{\mathrm{DFT}}$ are calculated using the experimental standard formation enthalpies, $\Delta \mathrm{G}^{0}$, of $\mathrm{GaSe}$ and $\mathrm{Cu}_{3} \mathrm{Se}_{2}$ as,

$$
\begin{gathered}
E_{\mathrm{Ga}}^{\mathrm{DFT}}=\left[E_{\mathrm{GaSe}}^{\mathrm{DFT}}-E_{\mathrm{Se}}^{\mathrm{DFT}}-\Delta G_{\mathrm{GaSe}}^{\circ}\right] \\
E_{\mathrm{Cu}}^{\mathrm{DFT}}=\frac{1}{3}\left[E_{\mathrm{Cu}_{3} \mathrm{Se}_{2}}^{\mathrm{DFT}}-2 E_{\mathrm{Se}}^{\mathrm{DFT}}-\Delta G_{\mathrm{Cu}_{3} \mathrm{Se}_{2}}^{\circ}\right]
\end{gathered}
$$

Since the values of $\Delta \mathrm{G}_{\mathrm{CuGa}_{5} \mathrm{Se}_{8}}^{\circ}$ and $\Delta \mathrm{G}_{\mathrm{CuGaSe}_{2}}^{\circ} \mathrm{eV}$ are not available from experiments, $E_{\mathrm{Ga}}^{\mathrm{DFT}}$ and $\mathrm{E}_{\mathrm{Cu}}^{\mathrm{DFT}}$ are used to estimate, the values of $\Delta \mathrm{G}_{\mathrm{CuGa}_{5} \mathrm{Se}_{8}}^{\circ}=-11.57 \mathrm{eV}$ and $\Delta \mathrm{G}_{\mathrm{CuGaSe}_{2}}^{\circ}=$ $-3.02 \mathrm{eV} . \Delta \mathrm{G}_{\mathrm{GaSe}}^{\circ}=-1.43 \mathrm{eV}$ was measured using combustion calorimetry [28], while $\Delta \mathrm{G}_{\mathrm{Cu}_{3} \mathrm{Se}_{2}}^{\circ}=$ $-1.67 \mathrm{eV}[29]$ and $\Delta \mathrm{G}_{\mathrm{Na}_{2} \mathrm{Se}}^{\circ}=-3.55 \mathrm{eV}[30]$ were estimated using differential thermal analysis.

Taking all these into consideration the expression for the surface energy -Equation 4 can be approximated as:

$$
\begin{aligned}
\gamma(T, p) & =\frac{1}{2 A}\left[E_{\mathrm{slab}}^{\mathrm{DFT}}-\left(\frac{n_{\mathrm{Se}}}{2}\right) E_{\mathrm{CuGaSe}_{2}}^{\mathrm{DFT}}\right. \\
& +\left(\left(\frac{n_{\mathrm{Se}}}{2}\right)-n_{\mathrm{Cu}}\right) E_{\mathrm{Cu}}^{\mathrm{DFT}}+\left(\left(\frac{n_{\mathrm{Se}}}{2}\right)-n_{\mathrm{Ga}}\right) E_{\mathrm{Ga}}^{\mathrm{DFT}} \\
& \left.+\left(\left(\frac{n_{\mathrm{Se}}}{2}\right)-n_{\mathrm{Cu}}\right) \Delta \mu_{\mathrm{Cu}}+\left(\left(\frac{n_{\mathrm{Se}}}{2}\right)-n_{\mathrm{Ga}}\right) \Delta \mu_{\mathrm{Ga}}\right]
\end{aligned}
$$

which is the expression we will use for calculating the surface energies.

\section{RESULTS AND DISCUSSION}

\section{A. $\mathrm{CuGaSe}_{2}$ Bulk}

Figure 2 shows the $\mathrm{CuGaSe}_{2}$ crystalline unit cell, and table $\mathrm{I}$ compares theoretical and experimental lattice parameters and band gaps. The first two lines show the theoretical lattice parameters calculated by us using the B3LYP [16, 17] and PBE [31] functionals. The lattice constants predicted using the B3LYP are overestimated by $2 \%$ and are in somewhat worse agreement with experiment than those predicted from the PBE GGA functional. This can be understood from the 


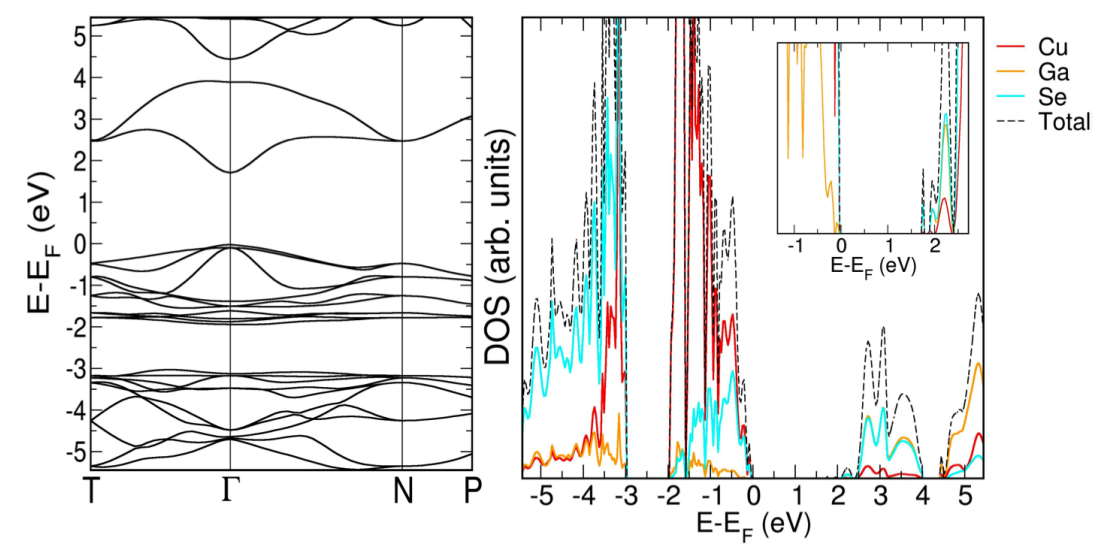

FIG. 1: (Color online) Band structure and atom-projected density of states (DOS) of bulk $\mathrm{CuGaSe}_{2}$. The inset at the top-right part of the DOS shows an amplified picture of the band-gap region.

$20 \%$ proportion of Fock exchange retained in the B3LYP functional. Increasing the proportion of exchange tends to decrease the lattice constant and open a larger band gap while compensating for electronic self interaction. On the other hand, the Heyd-Scuseria-Ernzerhof (HSE) [32] functional overestimates the values of the lattice parameters by a smaller amount, but gives a bandgap of $1.40 \mathrm{eV}$, which is significantly smaller than that observed.[60]

The points chosen for the BZ path for the band structure in Figure 1 are the high symmetry points $\mathrm{T}(0,0, \pi / \mathrm{a}), \Gamma(0,0,0), \mathrm{N}(\pi / \mathrm{a}, \pi / \mathrm{a}, 0)$ and $\mathrm{P}(\pi / \mathrm{a}, \pi / \mathrm{a}, \pi / 2 \mathrm{a})$. Our B3LYP calculations give a direct band gap of $1.73 \mathrm{eV}$, which is the theoretical value that best compares to the two experimental values reported in table If. These values were measured at room temperature using electroluminescence techniques [34] and a combination of ultraviolet photoelectron-and inverse-photoelectron-spectroscopy [36].

TABLE I: Comparison of Theoretical and Experimental Results

\begin{tabular}{|c|c|c|c|c|}
\hline & $a(\AA) \quad c(\AA)$ & $\eta=c$ & $\mathrm{E}_{g}(\mathrm{eV}$ & Ref. \\
\hline Theory, B3LYP & 5.73911 .311 & 0.985 & 1.73 & Our calc. \\
\hline Theory, PBE & 5.69211 .302 & 0.993 & 0.38 & Our calc. \\
\hline Theory, PBE & 5.68511 .220 & 0.987 & 0.03 & [33] \\
\hline Theory, HSE & 5.63711 .120 & 0.986 & 1.40 & [33] \\
\hline Experiment & 5.61611 .018 & 0.981 & 1.7 & [34] \\
\hline Experiment & 5.61411 .022 & 0.982 & 1.65 & {$[35,36$} \\
\hline
\end{tabular}




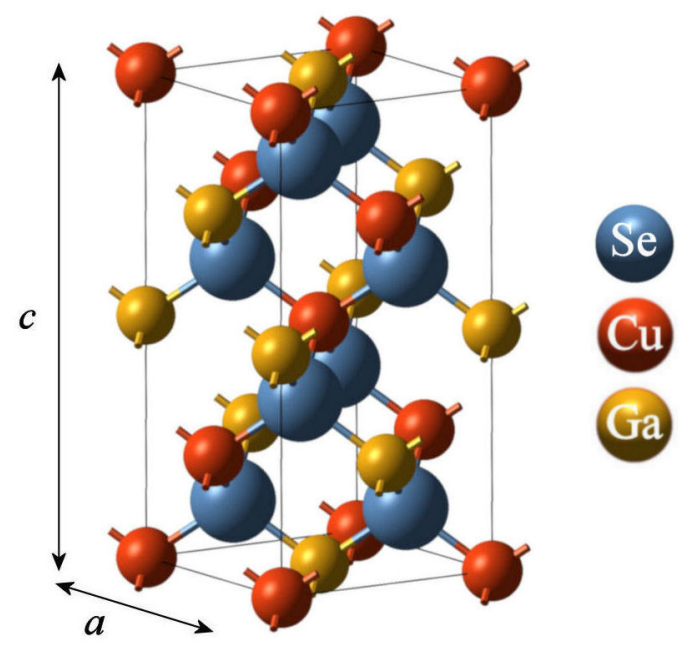

FIG. 2: (Color online) The (16 atom) conventional unit cell of $\mathrm{CuGaSe}_{2}$ is shown.

The calculated atom-projected density of states of $\mathrm{CuGaSe}_{2}$ is shown in Figure 1. Our results indicate that the valence band maximum is mainly composed $\mathrm{Cu} 3 \mathrm{~d}$ and $\mathrm{Se} 4 \mathrm{p}$ states, which is in agreement with the composition deduced from electroreflectance measurements[37] and with previous electronic structure calculations[38]. As regards the conduction band minimum, our results indicate that it is mainly formed by $\mathrm{Ga} 4 \mathrm{~s}, \mathrm{Cu} 4 \mathrm{~s}$ and $\mathrm{Se} 4 \mathrm{p}$ states, again in agreement with previous electronic calculations[39]. Moreover, the Mulliken bond population of tetrahedrally coordinated $\mathrm{Ga}$ and $\mathrm{Cu}$ in $\mathrm{CuGaSe}_{2}$ is 0.183 lel for the $\mathrm{Cu}-\mathrm{Se}$ bond and 0.268 lel for the $\mathrm{Ga}-\mathrm{Se}$ bond, indicating that $\mathrm{Ga}-\mathrm{Se}$ bonds are more covalent in nature than $\mathrm{Cu}-\mathrm{Se}$ bonds. These values can be compared to previous calculations of bond populations performed using Gaussian basis sets of a similar structure and quality. Previous CRYSTAL values of Mulliken populations for the (Mg, Al, Si)-O bond in $\mathrm{MgO}, \mathrm{Al}_{2} \mathrm{O}_{3}$ and $\mathrm{SiO}_{2}$ oxides are of the order of 0.01, 0.148 and 0.290[40]. This suggests a semi-ionic character for both the $\mathrm{Cu}$-Se and $\mathrm{Ga}-\mathrm{Se}$, which is in agreement with previous theoretical results [41-43]. 


\section{B. Phase Stability}

Figure 3 is the computed phase diagram as a function of the gallium and copper chemical potentials. It was calculated using the formalism described in section II B and highlights the stability region for $\mathrm{CuGaSe}_{2}$. This figure is a phase diagram projected in the $\left(\Delta \mu_{\mathrm{Cu}}, \Delta \mu_{\mathrm{Ga}}\right)$ plane. Within this plane, the value of $\Delta \mu_{\mathrm{Se}}$ is constrained by equations (6) and (7), and the diagonal line which links the $\Delta \mu_{\mathrm{Cu}}$ and $\Delta \mu_{\mathrm{Ga}}$ axes represents $\Delta \mu_{\mathrm{Se}}=0 \mathrm{eV}$. Points 1-2-3-4-5 indicate the corners of the stability region.

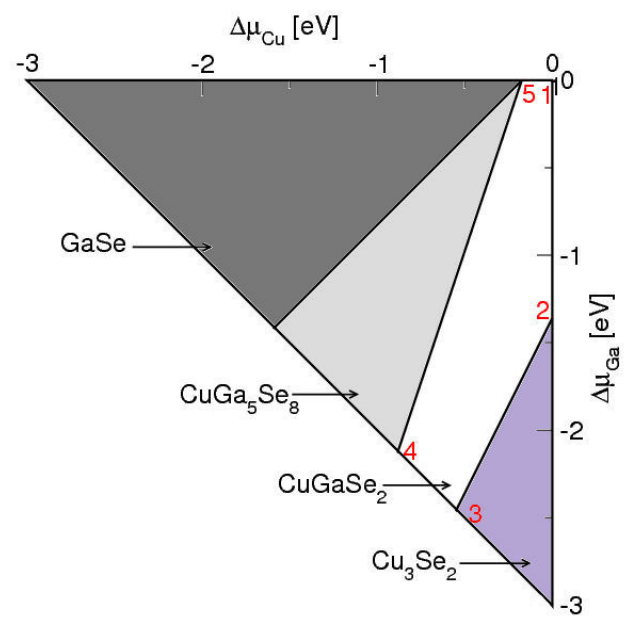

FIG. 3: (Color online) Calculated phase diagram for the $\mathrm{Cu}-\mathrm{Ga}$-Se system indicating the stable phases in the vicinity of $\mathrm{CuGaSe}_{2} . \Delta \mu_{\mathrm{Cu}}=0$ and $\Delta \mu_{\mathrm{Ga}}=0$ indicate $\mathrm{Cu}$-rich, Ga-rich regions, respectively. Since $\Delta \mu_{\mathrm{Se}}$ is defined through equations (6) and (7), the $\Delta \mu_{\mathrm{Cu}}=\Delta \mu_{\mathrm{Ga}}=0$ also indicates a Se-poor region. The diagonal line which links the $\Delta \mu_{\mathrm{Cu}}$ and $\Delta \mu_{\mathrm{Ga}}$ axes represents a selenium rich region with $\Delta \mu_{\mathrm{Se}}=0$

The $\mathrm{CuGaSe}_{2}$ phase diagram shown in Figure 3 can be compared to the one calculated by A. Zunger and coworkers [20]. The main general difference between Zunger's phase diagram and ours is the number of $\mathrm{CuGaSe}_{2}$ Õs competing phases considered. Zunger's diagram includes $\mathrm{Ga}_{2} \mathrm{Se}_{3}$ (tetragonal), $\mathrm{CuGa}_{5} \mathrm{Se}_{8}, \mathrm{GaSe}, \mathrm{Cu}_{3} \mathrm{Se}_{2}, \mathrm{CuSe}$ and $\mathrm{Cu}_{2} \mathrm{Se}$ as competing phases, while the phase diagram in Figure 3 includes $\mathrm{GaSe}, \mathrm{CuGa}_{5} \mathrm{Se}_{8}$ and $\mathrm{Cu}_{3} \mathrm{Se}_{2}$ : We did not include $\mathrm{Ga}_{2} \mathrm{Se}_{3}$ (tetragonal), $\mathrm{CuSe}$ and $\mathrm{Cu}_{2} \mathrm{Se}$. CuSe and $\mathrm{Cu}_{2} \mathrm{Se}$ were not included because they do not contribute to define the border of the stability region for $\mathrm{CuGaSe}_{2}$, but $\mathrm{Ga}_{2} \mathrm{Se}_{3}$ (tetragonal) could not be included.

In Zunger's methodology, the formation energies of the competing phases were calculated ab ini- 
tio, using the LDA functional. On the contrary, our methodology uses experimental formation energies. We could not find an experimental value for $\mathrm{Ga}_{2} \mathrm{Se}_{3}$ (tetragonal)'s formation energy. The ternary phase diagram of $\mathrm{CuGaSe}_{2}$ shows a $\mathrm{Ga}_{x} \mathrm{Se}_{3}$ competing phase with a small equilibrium region. $\mathrm{Ga}_{2} \mathrm{Se}_{3}$ as a bulk only exists as a $\mathrm{Ga}$-defective material, with a zincblende structure in which a third of the Ga sites are vacant. $\mathrm{Ga}_{2} \mathrm{Se}_{3}$ crystallizes into two forms: $\alpha$ and $\beta$. In the $\alpha$ form, vacancies are disordered throughout the crystal, whereas in the $\beta$-form the vacancies form an ordered arrangement. There are two phases of the vacancy-ordered $\beta-\mathrm{Ga}_{2} \mathrm{Se}_{3}$ : monoclinic and orthorhombic. The phase observed in the $\mathrm{CuGaSe}_{2}$ the ternary phase diagram was the monoclinic one.

\section{Surface Energies}

Figures 4 (a) and (b) show the relaxed, bulk-cut, Se-terminated and CuGa-terminated, fullyrelaxed $(1 \times 1)(001)$ surfaces of $\mathrm{CuGaSe}_{2}$. Figure 7 shows that the Se-terminated surface has lower energy than the CuGa-terminated surface for all environmental conditions. Figure 4 (a) shows that surface Se dimerise: This removes dangling bonds, lowering the surface energy. For the $\mathrm{CuGa}$-terminated slabs, there is electrostatic repulsion between the $\mathrm{Cu}$ and $\mathrm{Ga}$ atoms and the surface 'rumples'. The $\mathrm{Cu}$ atoms are displaced deeper into the Se layer below by about $1.186 \AA$ when compared to a $\mathrm{Cu}$ position in the bulk. Ga atoms are pushed out by approximately $0.582 \AA$ and as a result, the Ga-Se bond lengthens to $2.730 \AA$.
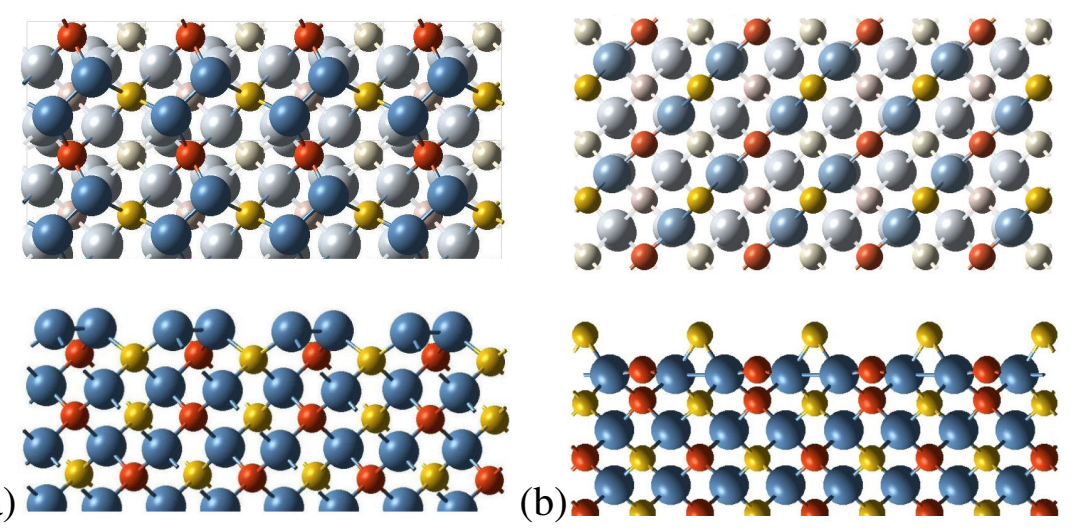

FIG. 4: (Color online) Top and lateral views of the relaxed: (a) Se-terminated and (b) CuGa-terminated $(1 \times 1)(001)$ surfaces of $\mathrm{CuGaSe}_{2}$. 


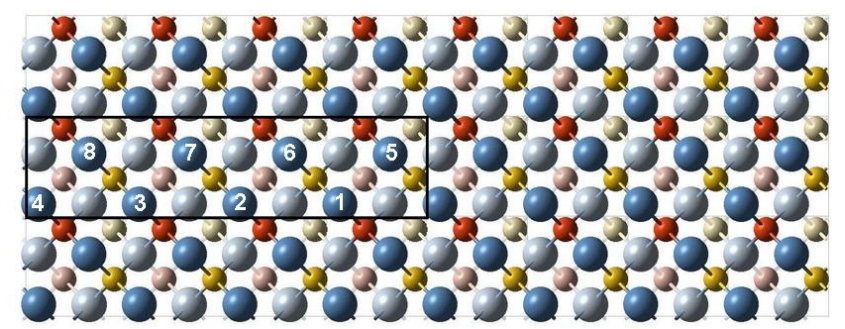

FIG. 5: (Color online) Unrelaxed Se-terminated $(1 \times 1)(001)$ surface. The black rectangle represents the $(4 \times 1)$ unit cell and the Se inside this cell are labeled 1-8.

Auger electron spectroscopy experiments suggest that the $(4 \times 1)$ surface reconstructions observed with LEED are $\mathrm{Cu}$-poor and Se-rich [9]. This suggests a model of the $(4 \times 1)$ reconstruction in which $\mathrm{Se}$ and $\mathrm{Cu}$ defects are introduced in the surface layers of a Se-terminated slab. Passivation with Sodium (Na) is important to the performance of the chalcopyrite absorber: $\mathrm{Na}$ is known to accumulate at the surface and grain boundaries [44] and, therefore, we have explored the stability of $\mathrm{Na}_{\mathrm{Cu}}$ defects. Figure 5 shows the top view of the unrelaxed Se-terminated (001) surface as a reference. The black rectangle indicates a $(4 \times 1)$ surface unit cell, the atomic positions of Se in the top layer are numbered from 1 to 8 . In Figure 6 top and side views of the reconstructions studied in this work are displayed.

Reconstruction 6(a) is a (001) CuSe-terminated surface that is generated by the removal of the top layer of $\mathrm{Ga}$ atoms from the CuGa-terminated surface shown in figure 4(b). Reconstruction 6(d) is nearly stoichiometric $\left(\mathrm{Cu}_{0.917} \mathrm{GaSe}_{2}\right)$ : It is made by removing four Se atoms at locations 2, 4, 6 and 8, and then the $\mathrm{Cu}$ atom below Se 2 and 6. In reconstruction 6(c) the $\mathrm{Cu}$ atom below Se 2 and Se 6 is replaced by Na: The reconstructions 6(d) and (c) do not display dimerisation of surface Se. On the contrary, reconstruction 6(b), which is made by removing two Se atoms at positions 2 and 6 and the $\mathrm{Cu}$ atom below, has a Se-rich stoichiometry of $\mathrm{Cu}_{0.917} \mathrm{GaSe}_{2.167}$ and presents dimerisation of the surface Se.

Figure (7) shows the surface energies of the ideal Se-terminated, CuGa-terminated and CuSeterminated $(1 \times 1)$ surfaces, plus the $(4 \times 1)(b),(c)$ and $(d)$ reconstructions. These surface energies are plotted as a function of the chemical potentials of $\mathrm{Se}, \mathrm{Cu}$ and $\mathrm{Ga}$, which are represented by the variables $\Delta \mu_{\mathrm{i}}$. These variables have been constrained to vary along the border of the stability 


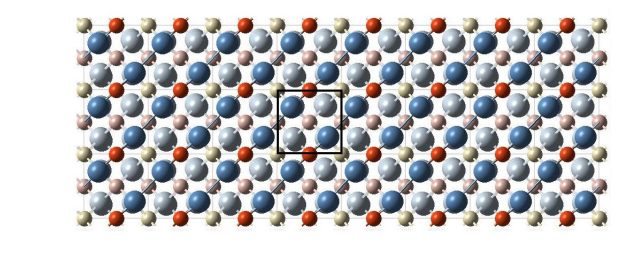

(a)
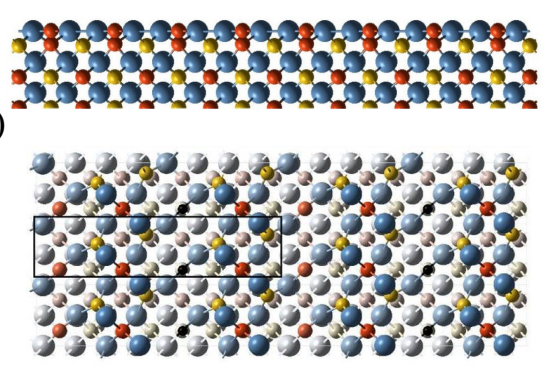

(b)

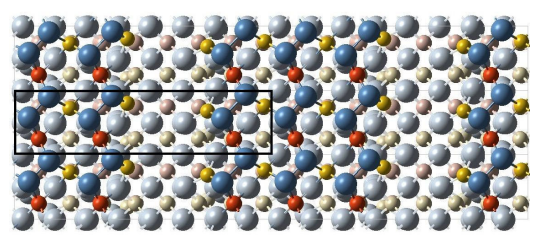

\section{(⿸丆口}

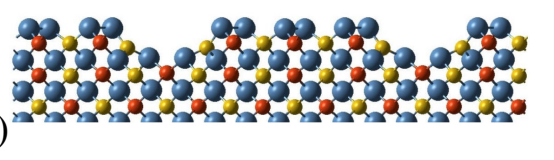

(c)
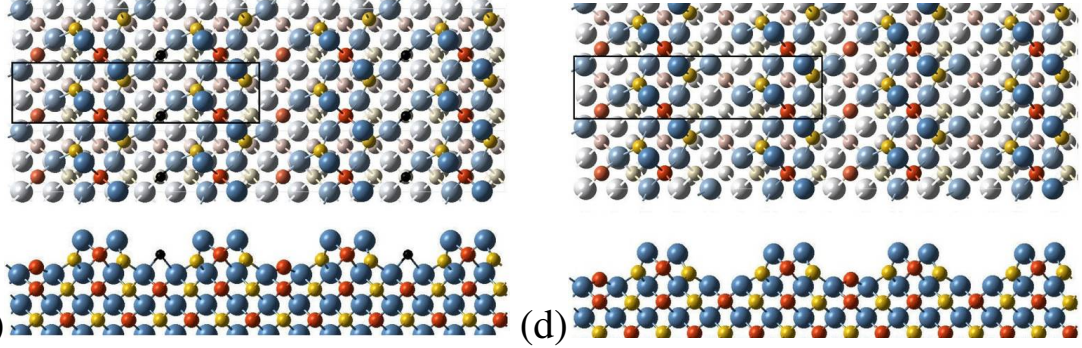

FIG. 6: (Color online) Studied surface reconstructions on the (001) surface of $\mathrm{CuGaSe}_{2}$. (a) is a $(1 \times 1)$ $\mathrm{CuSe}$-terminated surface generated by removing $\mathrm{Ga}$ atoms from the $(1 \times 1) \mathrm{CuGa}$-terminated surface. (b) is made by removing the Se atoms 2 and 6, and the $\mathrm{Cu}$ atom below them, from the unreconstructed Seterminated surface shown in figure 5 and has a $\mathrm{Cu}_{0.917} \mathrm{GaSe}_{2.167}$ stoichiometry. In reconstruction (c) $\mathrm{Se}$ atoms 2 and 6 are removed and the $\mathrm{Cu}$ atom below them is replaced by Na. Finally, (d) has a $\mathrm{Cu}_{0.917} \mathrm{GaSe}_{2}$ stoichiometry and it is made by removing four Se atoms at locations 2, 4, 6 and 8, and then the $\mathrm{Cu}$ atom below Se 2 and 6.

region set up in figure 3. In this figure, segments 1-5 and 1-2 represents the $\mathrm{Cu}$ and $\mathrm{Ga}$ rich regions, and segment 3-4 represents the Se rich region. Segment 2-3 ranges from intermediate conditions to the Se rich condition, and segment 4-5 encompasses both intermediate and extreme conditions.

The ideal $(1 \times 1)$ CuGa-terminated surface is unstable under all environmental conditions and has the highest surface energy amongst the surfaces modelled. The $(1 \times 1)$ Se-terminated surface is stable under most of the studied environmental conditions and at Se-rich conditions -along segment $3-4$ - it has the lowest surface energy of all reconstructions. The $(1 \times 1)$ CuSe-termination (a) has the same energy as the $(1 \times 1)$ CuGa-termination along the 5-1 segment, but otherwise is of lower energy than the CuGa-termination. Reconstruction $(4 \times 1)$ (d) is nearly stoichiometric and, as a result, its energy is relatively insensitive to the environmental conditions. The atomic structure of reconstruction $(4 \times 1)(c)$ is similar to reconstruction $(4 \times 1)(d)$, except that a $\mathrm{Na}$ atom is replacing a $\mathrm{Cu}$ atom in the surface layer. The surface energy of reconstruction $(4 \times 1)$ (c) is 


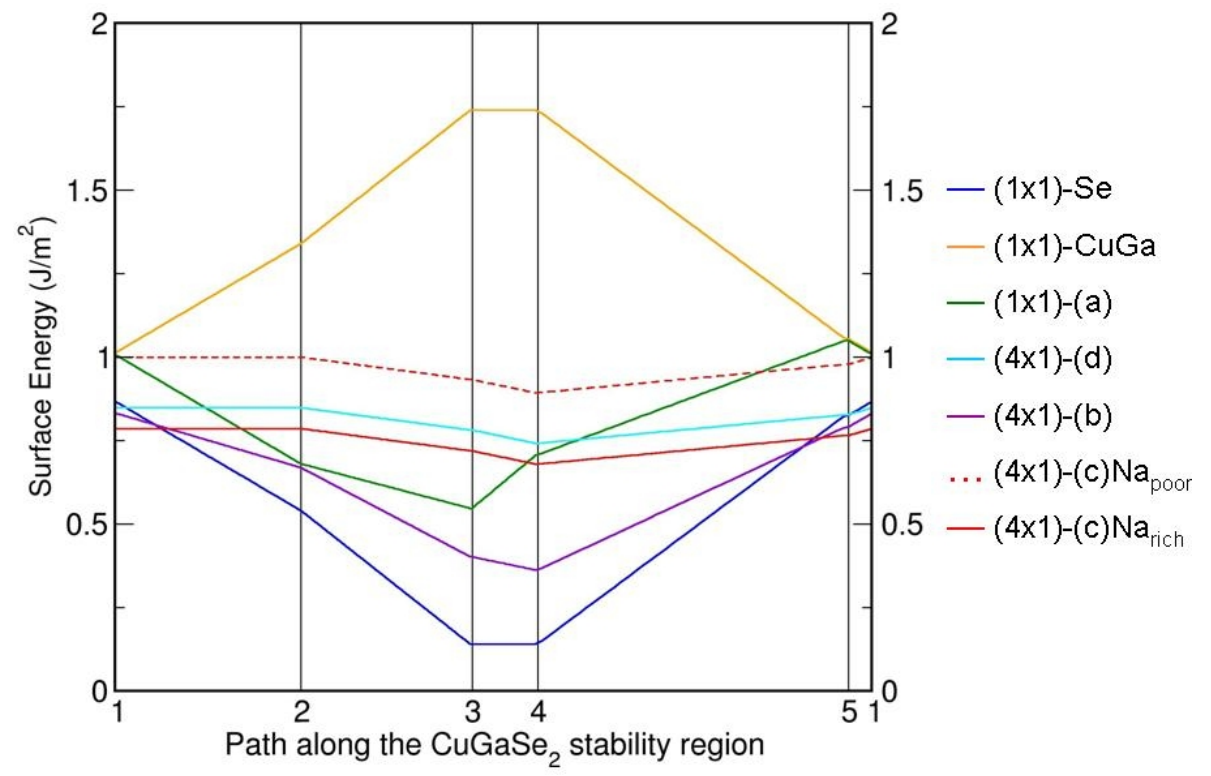

FIG. 7: (Color online) Surface energies of the ideal Se-terminated, CuGa-terminated and CuSe-terminated $(1 \times 1)$ surfaces, plus the $(4 \times 1)(b),(c)$ and $(d)$ reconstructions. These energies are plotted as a function of the chemical potentials of $\mathrm{Se}, \mathrm{Cu}$ and $\mathrm{Ga}$, which are constrained to vary along the border of the stability region set up in figure 3 .

plotted along the border of the stability region for the two limiting values of $\Delta \mu_{\mathrm{Na}}$ as defined in Section II B. Na has a stabilising effect on the reconstructions in the upper limits of $\Delta \mu_{\mathrm{Na}}$. As a result, in a Na-rich environment and under $\mathrm{Cu}$-rich, Ga-rich and Se-poor conditions (point 1 Figure (7)), reconstruction $(4 \times 1)(c)$ has the lowest surface energy.

We propose two complementary mechanisms for surface stabilisation. The first one is the ability of a surface reconstruction to coordinate $\mathrm{Ga}$ and $\mathrm{Cu}$ atoms at the surface, and the second one is the ability of the surface Se to eliminate dangling bonds. It is clear from figure (4) and figures (6) that $\mathrm{Cu}$ and $\mathrm{Ga}$ coordination is achieved with Se-terminated surfaces. The surface Se then eliminate dangling bonds through dimerisation. It is for this reason that the unreconstructed Se-terminated surface is stable for most environmental conditions. Except from the Se-poor environmental conditions described by region 5-1in figure 3, it is the $\mathrm{Cu}$ and $\mathrm{Ga}$ coordination to $\mathrm{Se}$ which dominates the surface energy, and this helps explain the low surface energies of reconstructions $(4 \times 1)(b)$ and Se-terminated $(1 \times 1)$, and the large surface energies of reconstructions $(4 \times 1)(d)$, $(4 \times 1)(c)$ and $(1 \times 1)(a)$. 

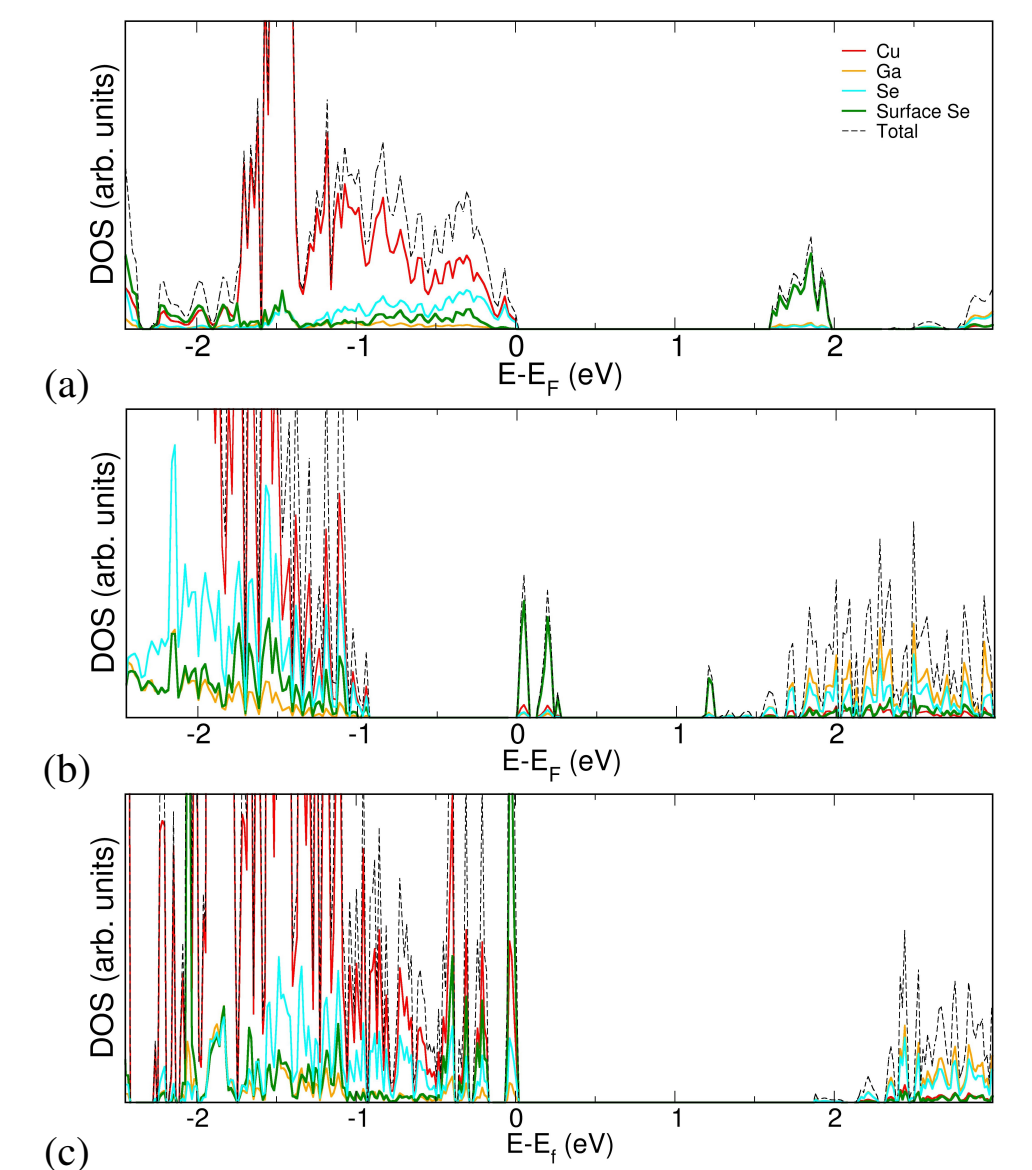

(c)

(d)

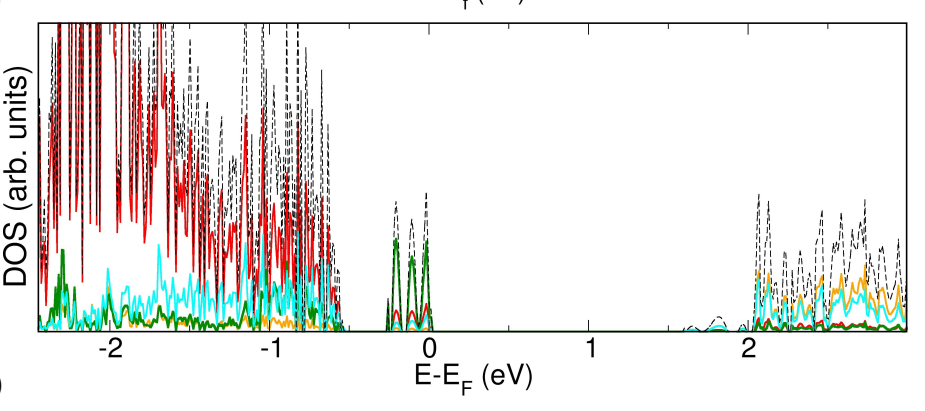

FIG. 8: (Color online) Projected densities of states (PDOS) of different surface reconstructions on the (001) surface of $\mathrm{CuGaSe}_{2}$. Figure (a) shows the PDOS of the $(1 \times 1)$ Se-terminated surface. Figures (b) (c) and (d) show the PDOS of the $(4 \times 1)$ reconstructions shown in figures $6(b),(c)$ and (d).

The effects of surface Se dimerisation can be seen in the corresponding partial density of states (PDOS), and in the bond population of the Se forming the dimers. In bulk chalcopyrite-type $\mathrm{CuGaSe}_{2}, \mathrm{Cu}$ and $\mathrm{Ga}$ are tetrahedrally coordinated by four Se atoms. There are bond populations of 0.268lel between $\mathrm{Ga}-\mathrm{Se}$ and 0.183 lel between $\mathrm{Cu}-\mathrm{Se}$, but between $\mathrm{Cu}-\mathrm{Cu}, \mathrm{Cu}-\mathrm{Ga}, \mathrm{Ga}-\mathrm{Ga}$ and Se-Se, the bond populations are of the order of at most 0.01 lel. For the $(1 \times 1)$ Se-terminated 
surface indicated in figure (4)(a), the bond population in the Se-dimers at the surface is 0.13lel. As regards the $(4 \times 1)$ reconstructions, only the Se dimers on surface 6 (b) (b) present a significant bond population of 0.128 el: in all the other $(4 \times 1)$ reconstructions, the bond population for the surface Se-Se contacts is negligible. Figures $(8)$ show the PDOS of the $(1 \times 1)$ and $(4 \times 1)$ surface reconstructions described in figures $(4)(a)$ and $(6)(b),(c)$ and $(d)$. The total DOS is projected onto contributions for $\mathrm{Ga}, \mathrm{Cu}$ and Se bulk atoms, and onto pairs of surface Se atoms which have the closest interatomic distances in all the slab, and which are likely to be forming surface dimers. The clearest signature of surface Se dimerisation is the anti-bonding states of the surface Se dimers, which are indicated by their PDOS. Figures $[8$ (a) and (b) show large peaks of surface Se PDOS above the Fermi energy. From a molecular orbital point of view, these peaks can be interpreted as empty antibonding orbitals of the surface Se dimers. These surface Se PDOS peaks disappear from the conduction band in figures $(8)(c)$ and (d), which indicates occupation of all the bonding and antibonding orbitals of the surface Se dimers, decreasing the covalent nature of the Se bonding at the surface. Except from the Se-poor environmental conditions described by region 5-1in figure 3, the surface energies of reconstructions $(8)$ (a), (b), (c) and )d), under most environmental conditions, is correlated with the bond population of its surface Se dimers: low surface energies are strongly related to high Se-Se bond populations.

It is well known that in chalcopyrites such as $\mathrm{CuAlS}_{2}$ [45], $\mathrm{CuGaS}_{2}$ [46], $\mathrm{CuInSe}_{2}$ and $\mathrm{CuGaSe}_{2}$ [47] $\mathrm{Cu}$ vacancies have the lowest formation energies under most environmental conditions. When chalcopyrites are doped with Na, AES evidence shows that Na tends to accumulate at the surfaces and grain boundaries[48]. An example of this is $\mathrm{CuInSe}_{2}$ : If available in large quantities, $\mathrm{Na}$ will replace $\mathrm{Cu}$ and form the more stable $\mathrm{NaInSe}_{2}$ compound, which will precipitate to form a separate phase; when available in small quantities, $\mathrm{Na}$ will replace $\mathrm{Cu}$ and In atoms, forming $\mathrm{Na}_{\mathrm{Cu}}$ and $\mathrm{Na}_{\mathrm{In}}$ defects. The concentration of of $\mathrm{Na} \mathrm{Cu}_{\mathrm{Cu}}$ defects is higher than the concentration of $\operatorname{In}_{C u}$ defects[49]. This results in the quenching of the $\operatorname{In}_{C u}$ and $\mathrm{V}_{\mathrm{Cu}}$ defects, which results in a decrease of the concentration of the $\left(2 \mathrm{~V}_{\mathrm{Cu}}^{-1}+\mathrm{In}_{\mathrm{Cu}}^{+2}\right)$ complex defect. The presence of small quantities of $\mathrm{Na}$ then contributes to the synthesis of $\mathrm{Cu}$-poor chalcopyrites, avoiding the formation of the so called ordered defective compounds]45], increasing the p-type 
layer conductivity [50], and reducing the dependence on the compositional ratio of $\mathrm{Cu} / \mathrm{In}$ [51].

Moreover, Na enhances key features of polycrystalline $\mathrm{Cu}(\mathrm{In} / \mathrm{Ga}) \mathrm{Se}_{2}$ (CIGS) thin-film solar cells, such as the fill factor (FF) and the open circuit voltage [52, 53]. Na is normally incorporated into CIGS films, during the deposition process, by thermal diffusion from a soda lime glass substrate. However, to improve performance of nonalkali-substrate-based CIGS solar cells, various methods for $\mathrm{Na}$ incorporation have been reported, including co-evaporation of $\mathrm{Na}$ compounds during CIGS deposition [51] and deposition of a $\mathrm{SiO}_{x}: \mathrm{Na}$ layer prior to Mo deposition [54]. Among these methods of $\mathrm{Na}$ incorporation, evaporating $\mathrm{NaF}$ is one of the most effective ways: In this method, Na diffusion into CIGS differs from that of soda lime glass, and high-quality CIGS films could be obtained at low temperature [55]. Na also has the ability to retain Se at the surface. Experimental evidence[56-58] shows that, at Na-rich conditions, $\mathrm{Na}$ is likely to be forming $\mathrm{Na}_{2} \mathrm{Se}$ which, in turn, will form $\mathrm{Na}$ polyselenides such as $\mathrm{Na}_{2} \mathrm{Se}_{2}$. The formation of $\mathrm{Na}_{2} \mathrm{Se}_{2}$ is an exothermic process and energy is needed to remove Se from the surface. The role of $\mathrm{Na}$ in chalcopyrites has been theoretically studied as well. Y. Yan and coworkers [59] used ab initio calculations to analyse the electronic structure of the CuInSe's grain boundaries, and they discussed the effect of $\mathrm{Na}$ in them. In particular, they defined a "segregation energy", that estimates how expensive is for a $\mathrm{Na}$ atom to diffuse into a grain boundary. No thermodynamics was used in the definition of this energy: they only used ab initio total energies, which restricted the range of possible segregation energy values to only one.

Se-dimerisation helps to explain surface stability under most environmental conditions, but not under the conditions the which $(4 \times 1)$ reconstructions were observed. LEED measurements show that $(4 \times 1)$ reconstructions form on $\mathrm{CuGaSe}_{2}(001)$ after several cycles of $\mathrm{Ar}^{+}$ion bombardment and subsequent annealing at UHV conditions. The observed surface reconstructions were clean, stable and unfacetted, with a Se-rich and $\mathrm{Cu}$-poor stoichiometry. [8] Since we assume Se is present in the gas phase, the experimental UHV conditions can be represented in our phase diagram by low values of the $\mu_{\mathrm{Se}}$. According to equations (7), region 5-1 in figure 3 has the lowest values of $\mu_{S e}$ that can be achieved in a $\mathrm{Cu}, \mathrm{Ga}$ and $\mathrm{Se}$ system. Under these conditions, reconstruction $(4 \times 1)(\mathrm{b})$ 
has a lower surface energy than Se-terminated $(1 \times 1)$ surface and, under Na-rich conditions, the stable surface reconstruction is reconstruction $(4 \times 1)(\mathrm{c})$. Both these surfaces have $\mathrm{Cu}$-poor and Se-rich stoichiometries of $\mathrm{Cu}_{0.97} \mathrm{GaSe}_{2.167}$ and $\mathrm{Cu}_{0.97} \mathrm{GaSe}_{2}$ respectively. The distance between the surface Se in reconstruction $(4 \times 1)(\mathrm{c})$ lengthen by an average of $0.261 \AA$ when compared to that of reconstruction $(4 \times 1)(b)$, and Se dimerisation at the surface has disappeared. The limiting values of $\Delta \mu_{\mathrm{Na}}$ are calculated combining equations $(10)$ and (11). Region 5-1 of figure 3 is a Na-rich region and, in it, reconstruction $(4 \times 1)(c)$ is predicted to be the stable one.

\section{CONCLUSIONS}

$A b$ initio thermodynamics has been used to study the stability of different surface reconstructions that were observed in $\mathrm{CuGaSe}_{2}(001)$. It has been shown that, for most environmental conditions, the presence of $\mathrm{Se}$ at the surface, with its ability to dimerise and coordinate $\mathrm{Cu}$ and $\mathrm{Ga}$ ions at the surface, it is the main mechanism stabilising the surface. In particular, the atomic structure of the experimentally observed $(4 \times 1)$ surface reconstructions can be described by $\mathrm{Cu}$-poor Se-rich reconstructions $(4 \times 1)(b)$ and (c), and it was established that the presence of Na stabilises the $(4 \times 1)$ reconstruction.

\section{ACKNOWLEDGEMENTS}

The calculations performed for this work were carried out in part on the facilities of Imperial College High Performance Computing Service (URL: http://www.imperial.ac.uk/ict/services/ teachingandresearchservices/highperformancecomputing), and in part on the national highperformance computing service of the UK, HECToR, where computer time has been provided via our membership of the HPC Materials Chemistry Consortium of the UK and funded by the EPSRC (portfolio Grant No EP/F067496).

This work was funded by the EPSRC under the "Nanostructured Functional Materials for Energy 
Efficient Refrigeration, Energy Harvesting and Production of Hydrogen from Water" grant (EP/G060940/1).

[1] U. Rau, K. Taretto and S. Siebentritt, Applied Physics A: Materials Science \& Processing, 2009, 96, $221-234$.

[2] P. Palacios, I. Aguilera, P. Wahnon and J. C. Conesa, Journal of Physical Chemistry C, 2008, 112, 9525-9529.

[3] S. Irvine, V. Barrioz, D. Lamb, E. Jones and R. Rowlands-Jones, Journal of Crystal Growth, 2008, 310, $5198-5203$.

[4] K. Ramanathan, M. A. Contreras, C. L. Perkins, S. Asher, F. S. Hasoon, J. Keane, D. Young, Romero, M., Metzger, W., R. Noufi, J. Ward and A. Duda, Progress in Photovoltaics: Research and Applications, 2003, 11, 225-230.

[5] I. Repins, M. A. Contreras, B. Egaas, C. DeHart, J. Scharf, C. L. Perkins, B. To and R. Noufi, Progress in Photovoltaics: Research and Applications, 2008, 16, 235.

[6] R. Hunger, C. Pettenkofer and R. Scheer, Surface Science, 2001, 477, 76-93.

[7] T. P. Massopoust, P. J. Ireland, L. L. Kazmerski and K. J. Bachmann, J. Vac. Sci. Technol. A, 1984, 2, 1123.

[8] T. Deniozou, N. Esser and S. Siebentritt, Surf. Sci., 2005, 579, 100 - 106.

[9] T. Deniozou, N. Esser, S. Siebentritt, P. Vogt and R. Hunger, Thin Solid Films, 2005, 480-481, 382 387.

[10] P. Tasker, J. Phys. C: Solid State Phys., 1979, 12, 4977.

[11] P. Corvini, A. Kahn and S. Wagner, J. Appl. Phys., 57, 2967.

[12] A. Meeder, L. Weinhardt, R. Stresing, D. F. Marrón, R. Würz, S. M. Babu, T. Schedel-Niedrig, M. C. Lux-Steiner, C. Heske and E. Umbach, Journal of Physics and Chemistry of Solids, 2003, 64, 1553 1557.

[13] S. Siebentritt, N. Papathanasiou, J. Albert and M. C. Lux-Steiner, Appl. Phys. Lett., 2006, 88, 151919. 
[14] J. A. AbuShama, S. Johnston, R. Ahrenkiel, R. Crandall, D. Young and R. Noufi, Evolution of Electronic Properties of (Cu(In,Ga)Se2 (CIGS)-Based Solar Cells During a 3-Stage Growth Process, 2003.

[15] R. Dovesi, V. R. Saunders, C. Roetti, R. Orlando, C. M. Zicovich-Wilson, F. Pascale, B. Civalleri, K. Doll, N. M. Harrison, I. J. Bush, P. D'Arco and M. Llunell, CRYSTAL 2006 Users's Manual, University of Torino, 2007.

[16] S. Tomić, B. Montanari and N. Harrison, Physica E, 2008, 40, 2125.

[17] Principles and Applications of Density Functional Theory in Inorganic Chemistry II, ed. N. Kaltsoyannis and J. McGrady, Springer, 2004, ch. The Performance of Hybrid Density Functionals in Solid State Chemistry, pp. 171-232.

[18] J. Muscat, A. Wander and N. M. Harrison, Chem. Phys. Letts., 2001, 342, 397.

[19] R. Dovesi, V. R. Saunders, C. Roetti, R. Orlando, C. M. Zicovich-Wilson, F. Pascale, B. Civalleri, K. Doll, N. M. Harrison, I. J. Bush, P. D'Arco and M. Llunell, CRYSTAL 2006 Users's Manual, University of Torino, 2007.

[20] C. Persson, Y.-J. Zhao, S. Lany and A. Zunger, Phys. Rev. B, 2005, 72, 035211.

[21] S. B. Zhang and S.-H. Wei, Physical Review Letters, 2004, 92, 086102.

[22] S. B. Zhang and S.-H. Wei, Physical Review B, 2002, 65, 081402.

[23] K. Reuter and M. Scheffler, Physical Review B, 2001, 65, 35406.

[24] K. Reuter and M. Scheffler, Physical Review B, 2003, 68, 45407.

[25] K. Reuter and M. Scheffler, Physical Review Letters, 2003, 90, 46103.

[26] B. Korzun, R. Mianzelen, A. Sheleg, N. Tekhanovich, K. Bente and W. Schmitz, Physica Status Solidi $B, 2005,242,1990$.

[27] B. Eckert and R. Steudel, Topics in Current Chemistry, 2003, 231, 31-98.

[28] F. Zheng, J. Shen, Y. Liu, W. Kim, M. Chu, M. Ider, X. Bao and T. Anderson, Calphad, 2008, 32, $432-438$.

[29] V. Glazov, A. Pashinkin and V. Fedorov, Inorganic Materials, 2000, 36, 641-652.

[30] F. Hergert, S. Jost, R. Hock, M. Purwins and J. Palm, Thin Solid Films, 2006, 511, 147-152.

[31] J. Perdew, Phys. Rev. Lett.; Physical Review Letters, 1996, 77, 3865-3868.

[32] J. Heyd, J. E. Peralta, G. E. Scuseria and R. L. Martin, The Journal of Chemical Physics, 2005, 123, 
174101.

[33] J. Paier, R. Asahi, A. Nagoya and G. Kresse, Phys. Rev. B, 2009, 79, 115126.

[34] G. Boyd, H. Kasper, J. McFee and F. Storz, 1972, 8, 900.

[35] L. Mandel, R. D. Tomlinson and M. J. Hampshire, Journal of Applied Crystallography, 1977, 10, 130 $-131$.

[36] A. Meeder, L. Weinhardt, R. Stresing, D. F. Marrón, R. Würz, S. M. Babu, T. Schedel-Niedrig, M. C. Lux-Steiner, C. Heske and E. Umbach, J. Phys. Chem. Solids, 2003, 64, 1553 - 1557.

[37] J. L. Shay, B. Tell, H. M. Kasper and L. M. Schiavone, Phys. Rev. B, 1972, 5, 5003-5005.

[38] S. Siebentritt, M. Igalson, C. Persson and S. Lany, Progress in Photovoltaics: Research and Applications, 2010, 18, 390-410.

[39] J. E. Jaffe and A. Zunger, Physical Review B, 1983, 28, 5822-5847.

[40] R. Dovesi, C. Roetti, C. Freyria-Fava, E. Apra, V. R. Saunders and N. M. Harrison, Phil. Trans. R. Soc. Lond. A, 1992, 341, 203.

[41] M. V.-G. C. Rincon, Materials Letters, 1996, 28, 297.

[42] H. Neumann, Crystal Research and Technology, 1983, 18, 1299.

[43] J. M. Merino, R. Diaz and M. Leon, Physical Review B, 2000, 61, 10211.

[44] D. Rudmann, A. F. da Cunha, M. Kaelin, F. Kurdesau, H. Zogg, A. N. Tiwari, and G. Bilger, Applied Physics Letters, 84, 1129-1131.

[45] L. Liborio and N. Harrison, Physical Review B, 2008, 77, 104104.

[46] C. Bailey, L. Liborio, G. Mallia, S. Tomic and N. M. Harrison, Phys. Rev. B, 2010, 81, year.

[47] C. Persson, Y. Zhao, S. Lany and A. Zunger, Phys. Rev. B, 2005, 72, 035211.

[48] D. W. Niles, M. Al-Jassim and K. Ramanathan, J. Vac. Sci. Technol. A, 1999, 17, 291.

[49] B. J. Stanberry, A. Davydov, C. H. Chang and T. j. Anderson, AIP Conference Proceeedings, 1996, p. 579.

[50] M. Contreras, B. Egaas, P. Dippo, J. Webb, J. Granata, K. Ramanathan, S. Asher, A. Swartzlander and R. Noufi, Photovoltaic Specialists Conference, 1997., Conference Record of the Twenty-Sixth IEEE, 1997, p. 359.

[51] T. Nakada, D. Iga, H. Ohbo and A. Kunioka, Jpn. J. Appl. Phys., 1997, 36, 732. 
[52] L. Stolt, J. Hedstrom, J. Kessler, M. Ruckh, K. Velthaus and H. W. Schock, Applied Physics Letters, 1993, 62, $597-599$.

[53] M. Ruckh, D. Schmid, M. Kaiser, R. Schaffler, T. Walter and H. Schock, Solar Energy Materials and Solar Cells, 1996, 41-42, 335.

[54] S. Ishizuka, A. Yamada, M. M. Islam, H. Shibata, P. Fons, T. Sakurai, K. Akimoto and S. Niki, J. Appl. Phys., 2009, 106, 034908.

[55] D. Rudmann, A. F. da Cunha, M. Kaelin, F. Kurdesau, H. Zogg, A. N. Tiwari, and G. Bilger, Appl. Phys. Lett., 2004, 84, 1129.

[56] F. Hergert, S. Jost, R. Hock, M. Purwins and J. Palm, Thin Solid Films, 2006, 511-512, 147 - 152.

[57] F. Hergert, R. Hock, A. Weber, M. Purwins, J. Palm and V. Probst, Journal of Physics and Chemistry of Solids, 2005, 66, 1903 - 1907.

[58] F. Hergert, S. Jost, R. Hock, M. Purwins and J. Palm, Thin Solid Films, 2007, 515, 5843 - 5847.

[59] Y. Yan, Phys. Rev. Lett.; Physical Review Letters, 2007, 99, year.

[60] We do not have a satisfactory explanation for the discrepancy between the PBE results for the bang gap. The paper by Paier et. al.[33] also presents PBE results for the $\mathrm{CuGaS}_{2}$. We have recently published a paper on the defects in $\mathrm{CuGaS}_{2}[46]$. The calculations in that paper were done using the B3LYP functional but, in order to document the performance of the PBE functional, we also performed PBE calculations on $\mathrm{CuGaS}_{2}$. We obtained a band gap of $0.79 \mathrm{eV}$ that compares very well with the $0.7 \mathrm{eV}$ obtained by Paier and coworkers. The problem, then, is apparently not due to the difference in the implementation of PBE in the codes used. Moreover, B3LYP gives us a reasonable value of the band gap of $\mathrm{CuGaSe}_{2}$, indicating that the discrepancy is unlikely to be due to inadequacies in the basis set or numerical conditions adopted in the current calculations. We had an exchange of emails with Paier and coworkers, and we believe that the remaining difference in the approaches is perhaps the Fermi surface smearing used by Paier et. al., which may have resulted in convergence to a near metallic state. 